Article

\title{
Breed Group Effects on Complaints about Canine Welfare Made to the Royal Society for the Prevention of Cruelty to Animals (RSPCA) Queensland, Australia
}

\author{
Hao Yu Shih ${ }^{1, *(\mathbb{D}, \text { Mandy B. A. Paterson }}{ }^{2}$ and Clive J. C. Phillips ${ }^{1}$ \\ 1 Centre for Animal Welfare and Ethics, University of Queensland, White House Building (8134), Gatton \\ Campus, Gatton, QLD 4343, Australia \\ 2 Royal Society for the Prevention of Cruelty to Animals Queensland, Brisbane, QLD 4076, Australia \\ * Correspondence: haoyu.shih@uqconnect.edu
}

Received: 20 May 2019; Accepted: 24 June 2019; Published: 26 June 2019

Simple Summary: This retrospective study involves 107,597 dog welfare complaints received by the Royal Society for the Prevention of Cruelty to Animals (RSPCA) Queensland from 2008 to 2018. Results show that, compared to pure breed dogs, cross-breed dogs were more likely to be reported in welfare complaints. Poisoning, lack of veterinary support, abuse, and being left unattended in a hot vehicle were common complaints in pure breed dogs; while insufficient shelter, exercise and food/water, as well as overcrowding and abandonment, were more commonly reported in cross breed dogs. Utility breeds, terriers and working dogs were most likely to be reported, while toy, non-sporting breeds and gundogs were least likely to be reported. Common complaint types for utility dogs were: insufficient food/water, shelter and exercise, and poor living conditions; for terriers: abandonment, intentional abuses and killing or injuring another animal; for working dogs: insufficient food/water, shelter and exercise; for toy dogs: lack of veterinary care, overcrowding and staying in a hot vehicle alone; for non-sporting dogs: lack of veterinary care, being left in a hot vehicle unattended and poor body conditions; and for hounds: killing or injuring another animal, intentional abuses and poor body conditions.

Abstract: Cruelty- and neglect-related canine welfare concerns are important welfare and social
issues. Dog breed has been identified as a risk factor for bad welfare, and yet its role in different types
of canine welfare concerns has not been fully investigated. We conducted a retrospective study of
$107,597 \mathrm{dog}$ welfare complaints received by RSPCA Queensland from July 2008 to June 2018. The
breed of the dog involved in the incident was either recorded as stated by the complainant or by the
inspector attending the case. Dog breed was divided into groups following the Australian National
Kennel Club nomenclature. Dogs of a non-recognised breed were more likely to be reported in
welfare complaints than recognised breed dogs. Recognised breed dogs had a greater risk of being
reported with poisoning, lack of veterinary support, abuse and being left unattended in a hot vehicle;
while non-recognised breed dogs had greater risk of being reported with insufficient shelter, exercise
and food/water, as well as overcrowding and abandonment. Utility breeds, terriers and working
dogs were most likely to be reported, while toy, non-sporting breeds and gundogs were least likely
to be reported. Common complaint types for utility dogs were: insufficient food/water, shelter and
exercise, and poor living conditions; for terriers: abandonment, intentional abuses and killing or
injuring another animal; for working dogs: insufficient food/water, shelter and exercise; for toy dogs:
lack of veterinary care, overcrowding and staying in a hot vehicle alone; for non-sporting dogs: lack
of veterinary care, being left in a hot vehicle unattended and poor body conditions; and for hounds:
killing or injuring another animal, intentional abuses and poor body conditions. Breed groups rather
than breeds may be the best method of breed identification in a public reporting system as they
group similar breeds together, and as our research shows, they relate to types of animal welfare
complaints. Understanding the relationship between breed group and canine welfare complaints 
may help authorities improve public education programs and inform decision-making around which breed a new owner should choose.

Keywords: canine welfare; breed; canine cruelty; neglect; RSPCA

\section{Introduction}

Animal cruelty can be defined as any socially [1] or legally [2] unacceptable behaviour causing unnecessary pain, discomfort or distress to animals. It is an important social issue, affecting not only animals but also the entire society, for example, there appears to be a strong relationship between animal cruelty and other criminal activities, such as domestic violence [3]. Animal cruelty can happen to any animal, and the dog (Canis familiaris) is one of the most common species reported for suspected animal cruelty [4].

For over 15,000 years, dogs have been domesticated to fit into our society with humans intentionally taming them, which facilitates the development of close bonds between humans and dogs $[5,6]$. According to the Australian National Kennel Club (ANKC), there are 208 recognised breeds that are categorised into seven breed groups-toys, terriers, gundogs, hounds, working dogs, utility, and non-sporting - on the basis of their physical characteristics, temperaments, behaviours, and functions [7]. For example, greyhounds were originally bred to chase and hunt in the Egyptian deserts 5000 years ago, and are categorised as hounds by the ANKC $[7,8]$. Border collies were selected for their sheep herding abilities in western Europe, northern England and Scotland over 100 years ago, and are classified as working dogs by the ANKC $[7,9,10]$. However, the original selection traits are often of little value today and their purpose has broadened to become purely aesthetic or related to entertainment (including gambling), causing them to experience some breed-specific mistreatments. For instance, greyhounds [11] and huskies [12] are used in the racing industry, and greyhounds have been widely reported to experience welfare issues associated with their training, living conditions and injuries during racing. The greyhound racing industry has been associated with "live baiting", where a live animal, such as a chicken or possum, is used as a lure to train greyhounds to race [11-13]. Border collies are popular for companionship, but their herding instincts may not be fulfilled in a home environment, which predisposes them to behavioural problems, such as bike or runner chasing, and can finally lead to unsuccessful ownerships [14]. Pit bull type dogs, such as the American pit bull terrier, American Staffordshire terrier and Staffordshire bull terrier are often thought of as aggressive [15]. These dogs may be made to participate in illegal dog fights or used for pig hunting, and animal management laws may be biased against them. In Australia, the importation of American pit bull terriers is banned [16] and the law requires all American pit bull terriers currently in Australia to be sterilised. In addition, these dogs must be kept strictly confined when at home, and when taken out be muzzled and wear easily identifiable collars $[15,17]$. Similarly, in America, some states (e.g., Indiana and Louisiana) require pit bull owners to obtain a special license and maintain $\$ 100,000$ to $\$ 300,000$ in liability insurance to cover any potential injuries caused by the dogs [18]. Many studies highlight the negative welfare that may be experienced by racing and fighting dogs $[17,19]$. The welfare issues they experience are not only breed specific, but are directly related to specific industries (e.g., dog racing and fighting) [20]. However, neglect-related issues, such as failing to provide suitable food and water, veterinary support and suitable living conditions, are more common, yet less discussed [3,21]. To our knowledge, there has been little consideration of the correlation between canine breed and different forms of animal welfare concerns, particularly those related to neglect.

Accurate breed identification is useful in many areas including in shelters, veterinary clinics, research, and even the media [22]. How dogs are identified influences the way they are perceived and how people interpret their behaviours [23-25]. For instance, dogs identified as terriers, especially American pit bull terriers and Staffordshire bull terriers are perceived as playful, curious, fearless, 
chase prone and aggressive; however, dogs identified as toy breeds are seen as sociable [25]. Current breed identification in the majority of facilities is based on observation, but such visual identification of breed is problematic and often inaccurate [22,26]. In a laboratory-based experiment, 986 people engaged in dog-related professions were asked to visually identify the breed of 20 dogs using video clips. The visual identification was later compared with DNA identification. The results showed that over $50 \%$ of participants failed to visually identify dog breeds that matched the DNA identification, and agreement by over $50 \%$ of participants was only found with $35 \%(n=7 / 20)$ of dogs [22]. Another study exploring inter-observer agreement among shelter staff differentiating pit-bull-type dogs versus non-pit-bull-type dog revealed moderate reliability (76\%-83\%) [26]. Consequently, a better breed identification method is needed, and identifying dogs per group or type (e.g., pit-bull type), rather than by specific breed, may result in higher agreement among individuals and be more useful.

In Queensland, Australia, animals are protected by the Animal Care and Protection Act 2001 (ACPA) [2]. This state-based legislation appoints inspectors, some of whom are employed by the Royal Society for the Prevention of Cruelty to Animals, Queensland (RSPCA Qld), to investigate potential breaches of, and enforce compliance with, the Act [2]. There are two main offences under the ACPA: failure to fulfil duty of care responsibilities and cruelty. There are a number of other specified offences. The Act recognises that a person who has charge of an animal owes that animal a duty of care. Failure to provide such care is the basis of the "breach of duty of care" offence. This offence covers such actions as not providing sufficient food, water, exercise, veterinary care and suitable living conditions. It is not only the owner that has a duty of care towards an animal. Anyone who is even temporarily in charge of an animal has a duty of care. The second major offence is "animal cruelty" and according to Section 18 of the Act, cruelty describes any action that causes unjustifiable and unnecessary physical and mental discomfort to animals, inappropriate confinement or transport, unreasonable injuries and inhumane death [2]. A cruel act can be committed by anyone towards an animal, whether it is their own animal, another domestic animal or even a wild animal [2]. It is important to note, that under the ACPA, the intention of a person to be cruel is not a necessary element of a cruelty offence to be proven in Queensland. If an action carried out by a person causes pain and suffering and the action was intentional, the person may be charged with cruelty. The intention to carry out the action must be proved but not the intention to be cruel. If a lack of action deprives an animal of its fundamental needs, then the person who has a duty of care towards the animal may be charged with a breach of their duty of care or cruelty depending on the circumstances. Intention may be considered during sentencing however [2]. Other offences under the Act include unreasonable abandonment or release, the carrying out of prohibited surgical procedures (e.g., tail docking, ear cropping, debarking, etc.), being involved in, or having items used for, a prohibited event, such as dog or cock fighting, and allowing an animal to injure or kill another animal [2].

The public can report suspected welfare concerns to the RSPCA via a "Cruelty Complaints" telephone number, which operates $24 \mathrm{~h}$ a day, seven days a week, or by email. In addition, complaints can be made by veterinarians and veterinary nurses, council officers, and other government and non-government employees visiting a location as part of their duties. Finally, animals entering a shelter may trigger an investigation if cruelty or neglect is suspected.

In this study, we aimed to evaluate whether breed was an important factor in relation to canine welfare concerns. This report is the second in a series relating to the analysis of RSPCA Qld canine welfare complaint data $[21,27]$. We hypothesized that certain breeds would have a higher risk of being reported. We also hypothesized that some breeds would be at higher risk of suffering specific welfare issues than others. Other risk factors, age of the dog [21] and socioeconomic status of the complainant are the subject of other papers [21,27]. 


\section{Materials and Methods}

From July 2008 to June 2018, RSPCA Qld received 129,036 canine welfare complaints. Some involving more than one dog were recorded as multiple complaints sharing the same case number, while others were recorded as one complaint with multiple animals. To avoid sample bias due to multiple entries, we only retained the first complaint of case numbers with multiple entries, discarding 21,439 entries as a result. There remained 107,597 canine welfare complaints for this retrospective study. The data analysis was originally undertaken on the entire dataset and then redone with the reduced number. Finding the complaint distribution and demographics to be similar, we opted for the reduced dataset to avoid problems with pseudoreplication. Animal welfare complaints that fell within the geographical zone of responsibility of RSPCA Qld (determined by a Memorandum of Understanding between RSPCA Qld and Biosecurity Queensland, the Government Department tasked with the administration of ACPA) were investigated by RSPCA Qld inspectors. All other complaints were referred to Biosecurity Queensland to be investigated by their inspectors. However, all complaints coming into RSPCA Qld were included in this analysis.

All complaints were recorded in ShelterBuddy ${ }^{\circledR}$ (RSPCA, Queensland, Australia), the RSPCA Qld database. The following information was requested from the reporter of each incident at the time of taking the complaint: the number of dogs involved and their age, breed(s) (if known), the "complaint code(s)", the suburb, postcode, and in addition, the date was recorded. All cases were investigated either by RSPCA Qld inspectors $(n=100,432)$ or Biosecurity Qld inspectors $(n=7165)$. It is recognized that some of the calls did not relate to a breach of the ACPA or to a genuine welfare concern. The outcome data for these complaints was not analysed in this research. This research is focused on the complaint calls coming in to RSPCA Qld.

Dogs were classified according to two broad age ranges, being dog and puppy, based on reporters' interpretation. It is important to recognise that the information recorded from the complainant may be inaccurate or inaccurately interpreted, e.g., a small dog is commonly referred to as a puppy in Queensland. Records regarding breed and the number of dogs involved were based on either complainants' initial reports or comments from trained inspectors, again recognising inaccuracies with identification of the breed. The "complaint code" was selected by the staff member receiving the call or email from a drop-down menu of 18 possible complaints (Appendix Table A1) [21]. Multiple "complaint codes" were able to be selected for each case according to the description of what was alleged to have happened to the $\operatorname{dog}(\mathrm{s})$, and each was treated as a separate code for analysis.

\subsection{Dog Breeds}

The distribution of breeds was compared to the breeds of registered dogs obtained from the councils of two cities situated close to the RSPCA Qld headquarters, namely Ipswich City Council and Gold Coast City Council for the same period. Any breed in our data that was documented in any of the following kennel clubs-Australian National Kennel Council (ANKC) [7], New Zealand Kennel Club (NZKC) [28], American Kennel Club (AMKC) [29] and United Kennel Club (UKC) [30]—was considered a recognised breed (RB) and was added to our breed list (Appendix Table A2). Any breed in our data that was not recognised by at least one of the major kennel clubs listed above was classified as a non-recognised breed (N-RB), including all crossbred dogs without any identified breed. In our dataset, it was decided that if more than one dominant breed was listed, the first breed mentioned would be used. For instance, Great Dane $\times$ Bull Arab was categorized as Great Dane (Appendix Table A2).

To achieve a secondary representation of breed recognition, RB breeds were amalgamated into the following seven breed groups based on the breed inclusion categories of the ANKC: toys, terriers, gundogs, hounds, working dogs, utility, and non-sporting. Breeds not listed by the ANKC, but recognised by the NZKC, AMKC, or UKC, were categorized into one of the seven groups based on the description of each kennel club. Some breeds (e.g., Australian Koolie and Bull Arab), though listed by the council registrations and thus on the breed list (Appendix Table A2), were not recognized as breeds 
by any major kennel club worldwide. Therefore, these breeds were categorized as N-RB. If the breed description was left blank, the dogs' breed was considered unknown ( $n=15,576 / 107,597)$, and these complaints were excluded from any data analysis related to breed factors.

\subsection{Statistical Analysis}

Data was analysed using the statistical package Minitab ${ }^{\circledR}$ 17.3.1. (Minitab, LLC., State College, PA, USA) Descriptive analysis was first used to investigate the distribution of RB/N-RB and the seven breed groups. Complaints reported in July 2017 and June 2018 that contained breed information provided by RSPCA inspectors $(n=95)$ were used to examine the agreement of breed identification between the complainant and inspectors. Apart from simple percent agreement measurements, Cohen's kappa coefficient was calculated. Cohen's kappa is a statistical method measuring agreement with qualitative assessments among different raters. It is more robust than a percentage because it considers the possibility of the agreement occurring by chance [26,31]. To examine whether RB, N-RB or certain breed groups were more likely to be reported, the study group was compared with the registration data from Gold Coast and Ipswich City councils where all owned dogs, including working dogs on farms, are required to be registered [32,33]; this was done using Pearson chi-square tests. Eighteen stepwise forward binary logistic regression models were constructed to understand how breed factors correlated with each complaint code. The binary logistic regression model is a nonlinear model using a logistic function to describe the relationship of independent variables and a dependent variable with two possible values, such as yes/no, 0/1, or healthy/sick [34]. The stepwise forward selection refers to a step-by-step method of adding the most significant dependent variable into the model [35]. To determine the effect of breed (RB/N-RB or breed group) on complaint codes, breed (RB/N-RB or breed group) was entered into the binary logistic regression model as a fixed factor, using logit models with the alpha value to enter being 0.15 . Complaint codes were entered into the model as outcomes. Separate models were constructed for each complaint code with the same input variable.

\section{Results}

\subsection{Dog Characteristics}

Common breeds reported by the complainants were Staffordshire bull terrier $(10.5 \%, n=10 / 95)$, American Staffordshire terrier $(10.5 \%, n=10 / 95)$, Maltese $(6.3 \%, n=6 / 95)$, and Bullmastiff $(5.3 \%$, $n=5 / 95)$. Overall, the agreement between complainants and inspectors of breed identification was 23.2\% (Cohen's Kappa $=0.074$, indicating a slight agreement [31]), and the agreement of breed group identification was 77.8\% (Cohen's Kappa $=0.69$, indicating a substantial agreement [31]). Therefore, breed groups were used for further analyses.

In the study group, $32.7 \%(n=35,178)$ of dogs were N-RB, while only $1.7 \%(n=1733)$ of dogs in the Gold Coast and Ipswich councils' data were listed as N-RB. Around 53\% $(n=56,843)$ of dogs in our data and $98.3 \%(n=99,266)$ of dogs in the councils' data were of RB (Table 1$)$. The remaining dogs $(14.5 \%, n=15,576)$ in our database were unspecified. Thus, there was an over-representation of N-RB and an under-representation of RB in our dataset. The most common breed group to be reported for canine welfare concerns in our dataset were terriers $(28.2 \%, n=16,030)$, followed by working dogs $(24.8 \%, n=14,085)$, utility dogs $(15.6 \%, n=8,857)$, toy dogs $(9.2 \%, n=5223)$, non-sporting dogs $(8.9 \%$, $n=5071)$, gundogs $(7.8 \%, \mathrm{n}=4417)$, and hounds $(5.6 \%, n=3160)$ (Table 2$)$. The most common breed group registered by the city councils were also terriers $(22.2 \%, n=22,056)$, but followed by toy dogs $(21.0 \%, n=20,796)$, working dogs $(17.8 \%, n=17,637)$, non-sporting dogs $(14.0 \%, n=13,915)$, gundogs $(11.6 \%, n=11,504)$, utility dogs $(7.8 \%, n=7770)$, and hounds $(5.6 \%, n=5581)$ (Table 2$)$. 
Table 1. Distribution of RB and N-RB in our study group, and in the Ipswich City Council and Gold Coast City Council registrations, with the overrepresentation coefficient (both RB and N-RB were significantly different (chi-square $p<0.001)$.

\begin{tabular}{cccc}
\hline Breed & Study Group & Ipswich and Gold Coast & Overrepresentation Coefficient $^{\text {a }}$ \\
\hline N-RB & $35,178(32.7 \%)$ & $1733(1.7 \%)$ & 19.24 \\
RB & $56,843(52.8 \%)$ & $99,266(98.3 \%)$ & 0.54 \\
Unknown & $15,576(14.5 \%)$ & $0(0 \%)$ & $-\mathrm{b}$ \\
Total & $107,597(100 \%)$ & $100,999(100 \%)$ & \\
\hline
\end{tabular}

a Percent of breeds in our study/percent of breeds in the councils' registrations. 1.00 signifies equal representation in our database, and Ipswich and Gold Coast City Councils registrations. ${ }^{b}$ Unable to calculate the overrepresentation coefficient because there was no dog with an unknown breed in the councils' data.

Table 2. Distribution of each breed group in our study, and in Ipswich City Council and Gold Coast City Council registrations, with the overrepresentation coefficient.

\begin{tabular}{ccccc}
\hline Breed Groups & RSPCA & Ipswich and Gold Coast & $\begin{array}{c}\text { Overrepresentation } \\
\text { Coefficient }{ }^{\text {a }}\end{array}$ & $\begin{array}{c}p \text {-Value } \\
\text { (Chi-Square Tests) }\end{array}$ \\
\hline Terriers & $16,030(28.2 \%)$ & $22,056(22.2 \%)$ & 1.27 & $<0.001$ \\
Working Dogs & $14,085(24.8 \%)$ & $17,637(17.8 \%)$ & 1.39 & $<0.001$ \\
Utility & $8857(15.6 \%)$ & $7770(7.8 \%)$ & 1.99 & $<0.001$ \\
Toys & $5223(9.2 \%)$ & $20,796(21.0 \%)$ & 0.44 & $<0.001$ \\
Non-sporting & $5071(8.9 \%)$ & $13,915(14.0 \%)$ & 0.64 & $<0.001$ \\
Gundogs & $4417(7.8 \%)$ & $11,504(11.6 \%)$ & 0.67 & 0.001 \\
Hounds & $3160(5.6 \%)$ & $5581(5.6 \%)$ & 0.99 & 0.602 \\
Total & $56,843(100 \%)$ & $99,266(100 \%)$ & & \\
\hline
\end{tabular}

${ }^{\text {a }}$ Percent of breeds in our study/percent of breeds in the councils' registrations. 1.00 signifies equal representation in our database, and Ipswich and Gold Coast City Councils registrations.

\subsection{Predispositions of $R B / N-R B$ to Welfare Complaints}

Table 1 summarizes the numbers and percentages of RB and N-RB in our data and the councils data, along with the overrepresentation coefficients. This coefficient is a simple method to compare the two percentages (see explanation below Table 1). Our results indicate that N-RB were at a greater risk of being reported than RB $(p<0.001)$.

We further explored the association between RB/N-RB and different complaint codes. A logistic regression model was generated (Table 3). In the model, there were significant correlations between $\mathrm{RB} / \mathrm{N}-\mathrm{RB}$ and nine $(n=9 / 18)$ complaint codes. RB had significantly greater risk of being reported with the following complaint codes, listed in increasing order of odds ratio (OR): baiting/poisoning ( $\mathrm{OR}=0.36, p<0.001)$, no treatment $(\mathrm{OR}=0.59, p<0.001)$, cruelty $(\mathrm{OR}=0.95, p=0.004)$, and hot animal in car $(\mathrm{OR}=0.95, p=0.043)$. Meanwhile, $\mathrm{N}-\mathrm{RB}$ had significantly greater risks of experiencing the following complaint codes, listed in declining order of odds ratio (OR): no exercise/confined/tethered $(\mathrm{OR}=1.32, p<0.001)$, overcrowding $(\mathrm{OR}=1.32, p<0.001)$, abandonment $(\mathrm{OR}=1.25, p<0.001)$, no shelter (OR $=1.19, p<0.001)$, and insufficient food and/or water ( $\mathrm{OR}=1.08, p<0.001)$. 
Table 3. Odds ratio of each variable in the logistic regression model of complaint codes. The outputs of these models were different complaint codes. The input variables were N-RB/RB and breed groups.

\begin{tabular}{|c|c|c|}
\hline Complaint Code & $\begin{array}{c}\mathrm{N}-\mathrm{RB} / \mathrm{RB} \\
p \text {-Value/or (CI) }{ }^{\text {a }}\end{array}$ & Breed Group $p$-Value \\
\hline Emergency relief & $-{ }^{c}$ & $-{ }^{c}$ \\
\hline Hot animal in car & $0.043 / 0.95(0.90,1.00)$ & $<0.001$ \\
\hline Keeping or using animal for blooding/coursing a dog & $-\mathrm{c}$ & $-{ }^{c}$ \\
\hline Prohibition order breached & $-{ }^{c}$ & $-{ }^{c}$ \\
\hline Causing captive animal to be injured/killed by dog & $-{ }^{c}$ & $-{ }^{c}$ \\
\hline Poor dog condition & $-{ }^{c}$ & $<0.001$ \\
\hline Overcrowding & $<0.001 / 1.32(1.14,1.53)$ & $<0.001$ \\
\hline No exercise/confined/tethered & $<0.001 / 1.32(1.28,1.36)$ & $<0.001$ \\
\hline Insufficient food and/or water & $<0.001 / 1.08(1.05,1.12)$ & $<0.001$ \\
\hline Baiting/poisoning & $<0.001 / 0.36(0.30,0.43)$ & $<0.001$ \\
\hline Tail docking or other surgical procedure & $-{ }^{c}$ & $-{ }^{c}$ \\
\hline No treatment & $<0.001 / 0.59(0.57,0.62)$ & $<0.001$ \\
\hline Dog fighting or other prohibited offence & $0.134 / 0.79(0.58,1.08)$ & $-{ }^{c}$ \\
\hline No shelter & $<0.001 / 1.19(1.14,1.24)$ & $<0.001$ \\
\hline Poor living condition & $-\mathrm{c}$ & 0.046 \\
\hline Cruelty $^{\mathrm{d}}$ & $0.004 / 0.95(0.91,0.98)$ & $<0.001$ \\
\hline Abandonment & $<0.001 / 1.25(1.21,1.29)$ & $<0.001$ \\
\hline Knowingly allowing an animal to kill/injure another & $0.111 / 0.86(0.71,1.04)$ & $<0.001$ \\
\hline
\end{tabular}

${ }^{\mathrm{a}}$ Odds ratio refers to $\mathrm{N}-\mathrm{RB}$ relative to $\mathrm{RB} ;{ }^{\mathrm{b}}$ Odds ratio and the $95 \%$ confidence interval (CI) of each breed group for every complaint code are presented in Table 4 ; ${ }^{\mathrm{C}}$ Breed factor (N-RB/RB or breed group) was not selected in the logistic regression model; ${ }^{\mathrm{d}}$ A person was reported to have abused an animal.

\subsection{Predispositions of Breed Groups to Welfare Complaints}

When we compared the numbers of different breed groups in our data with the councils' data (Table 2), the following breed groups were over-represented in our data, listed in declining order of overrepresentation coefficient $(p<0.001)$ : utility, working dogs and terriers. The following breeds in our database listed in increasing order of overrepresentation coefficient were underrepresented $(p<0.001)$ : toys, non-sporting and gundogs.

In the regression model (Table 3$)$, twelve $(n=12 / 18)$ complaint codes were predicted by breed group. Detailed results related to breed groups are summarized in Table 4. Toy dogs were more likely to be the subject of: no treatment, hot animal in car and overcrowding; terriers to: abandonment, cruelty, and knowingly allow an animal to kill/injure another; utility dogs to: insufficient food and/or water, no shelter, no exercise/confined/tethered and poor living condition; non-sporting dogs to: no treatment, hot animal in car and poor dog condition; hounds to: knowingly allow an animal to kill/injure another, cruelty and poor dog condition; and working dogs to: no exercise/confined/tethered, no shelter and insufficient food and/or water. 
Table 4. Odds ratio and the $95 \%$ confidence interval (CI) of each breed group for every complaint code.

\begin{tabular}{|c|c|c|c|c|c|c|c|c|c|c|c|c|}
\hline & No Treatment & Abandoned & Cruelty a & $\begin{array}{l}\text { Insufficient } \\
\text { Food and/or } \\
\text { Water }\end{array}$ & No Shelter & $\begin{array}{l}\text { No Exercise/ } \\
\text { Confined/ } \\
\text { Tethered }\end{array}$ & $\begin{array}{l}\text { Hot Animal in } \\
\text { Car }\end{array}$ & $\begin{array}{l}\text { Baiting and } \\
\text { Poisoning }\end{array}$ & $\begin{array}{l}\text { Poor Dog } \\
\text { Condition }\end{array}$ & Overcrowding & $\begin{array}{c}\text { Knowingly } \\
\text { Allowing an } \\
\text { Animal to } \\
\text { Kill/Injure } \\
\text { Another }\end{array}$ & $\begin{array}{l}\text { Poor Living } \\
\text { Condition }\end{array}$ \\
\hline Hounds/Gundogs & $1.00(0.89,1.12)$ & $0.92(0.82,1.04)$ & $1.17(1.03,1.33)$ & $0.96(0.87,1.07)$ & $0.74(0.64,0.85)$ & $1.10(0.99,1.23)$ & $0.82(0.68,0.99)$ & $0.77(0.54,1.12)$ & $1.47(1.32,1.62)$ & $1.56(0.94,2.57)$ & $2.44(1.38,4.29)$ & $1.10(0.97,1.24)$ \\
\hline Non-Sporting/Gundogs & $1.31(1.19,1.45)$ & $0.94(0.85,1.05)$ & $0.83(0.74,0.94)$ & $0.88(0.80,0.96)$ & $0.67(0.59,0.76)$ & $0.75(0.68,0.83)$ & $1.62(1.41,1.87)$ & $0.67(0.48,0.94)$ & $1.65(1.51,1.80)$ & $1.12(0.69,1.80)$ & $0.55(0.27,1.13)$ & $1.05(0.94,1.17)$ \\
\hline Terrier/Gundogs & $1.31(1.19,1.45)$ & $1.08(0.99,1.18)$ & $1.28(1.16,1.41)$ & $1.01(0.94,1.09)$ & $0.88(0.80,0.97)$ & $1.06(0.98,1.15)$ & $1.22(1.08,1.38)$ & $0.49(0.37,0.64)$ & $1.01(0.94,1.09)$ & $0.70(0.46,1.06)$ & $1.76(1.08,2.85)$ & $1.02(0.94,1.12)$ \\
\hline Toys/Gundogs & $1.50(1.36,1.66)$ & $0.92(0.83,1.02)$ & $0.97(0.86,1.08)$ & $0.63(0.58,0.70)$ & $0.41(0.36,0.48)$ & $0.51(0.46,0.57)$ & $2.67(2.34,3.05)$ & $0.85(0.62,1.16)$ & $1.07(0.97,1.17)$ & $2.08(1.35,3.20)$ & $0.71(0.36,1.38)$ & $0.98(0.88,1.09)$ \\
\hline Utility/Gundogs & $0.98(0.89,1.07)$ & $1.03(0.94,1.13)$ & $1.01(0.91,1.12)$ & $1.12(1.03,1.22)$ & $1.13(1.02,1.26)$ & $1.38(1.26,1.50)$ & $0.49(0.42,0.57)$ & $0.50(0.36,0.68)$ & $1.45(1.34,1.57)$ & $0.76(0.48,1.20)$ & $1.21(0.71,2.06)$ & $1.10(1.00,1.21)$ \\
\hline Working Dogs/Gundogs & $0.93(0.85,1.01)$ & $0.95(0.87,1.03)$ & $1.15(1.04,1.26)$ & $1.01(0.93,1.09)$ & $1.09(0.99,1.20)$ & $1.32(1.22,1.43)$ & $0.97(0.85,1.10)$ & $0.65(0.50,0.85)$ & $1.13(1.04,1.22)$ & $1.22(0.82,1.83)$ & $1.19(0.71,1.97)$ & $1.09(0.99,1.19)$ \\
\hline Non-Sporting/Hounds & $1.31(1.18,1.46)$ & $1.02(0.91,1.15)$ & $0.71(0.62,0.81)$ & $0.91(0.82,1.01)$ & $0.91(0.78,1.05)$ & $0.68(0.61,0.76)$ & $1.97(1.66,2.34)$ & $0.87(0.59,1.28)$ & $1.13(1.03,1.24)$ & $0.72(0.45,1.15)$ & $0.22(0.12,0.44)$ & $0.96(0.85,1.07)$ \\
\hline Terrier/Hounds & $1.06(0.96,1.17)$ & $1.17(1.06,1.30)$ & $1.09(0.98,1.21)$ & $1.05(0.96,1.14)$ & $1.19(1.05,1.35)$ & $0.96(0.88,1.05)$ & $1.49(1.27,1.73)$ & $0.63(0.45,0.88)$ & $0.69(0.64,0.75)$ & $0.45(0.30,0.68)$ & $0.72(0.49,1.06)$ & $0.93(0.84,1.03)$ \\
\hline Toys/Hounds & $1.51(1.35,1.68)$ & $1.00(0.89,1.12)$ & $0.82(0.73,0.93)$ & $0.66(0.59,0.73)$ & $0.56(0.48,0.66)$ & $0.47(0.42,0.52)$ & $3.25(2.76,3.82)$ & $1.10(0.76,1.59)$ & $0.73(0.66,0.80)$ & $1.33(0.87,2.03)$ & $0.29(0.16,0.53)$ & $0.89(0.80,1.00)$ \\
\hline Utility/F & $0.98(0.88,1.09)$ & $1.12(1.00,1.24)$ & $0.86(0.77,0.96)$ & $6(1.06,1.28)$ & $1.54(1.35,1.75)$ & $1.25(1.14,1.37)$ & $0.60(0.49,0.72)$ & $0.64(0.44,0.93)$ & $0.99(0.91,1.08)$ & $0.49(0.31,0.77)$ & $0.50(0.32,0.78)$ & $1.00(0.90,1.12)$ \\
\hline Working $\mathrm{I}$ & & $3,1.13)$ & $98(0.88,1.09)$ & $(0.95,1.14)$ & $8(1.31,1.68)$ & $1.20(1.09,1.31)$ & $1.17(1.00,1.38)$ & 88440 & $0.77(0.71$ & 0.78 & 0.49 & \\
\hline Ter & & 1. & & & 1.46) & $1.41(1.30$ & $(0.68,0.84)$ & 8) & 66) & & & \\
\hline To & $1.15(1.05,1.25)$ & $0.98(0$ & $1.16(1$ & )) & 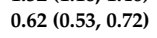 & 0. & $47,1.85)$ & & & & & $1.04)$ \\
\hline Utility/Non-Sporting & $0.75(0.69,0.81)$ & $1.09(1.00,1.19)$ & $1.21(1.09,1.34)$ & $1.28(1.18,1.39)$ & $1.70(1.52,1.90)$ & $1.83(1.68,1.99)$ & $0.30(0.26,0.35)$ & $0.74(0.53,1.03)$ & $0.88(0.82,0.94)$ & $0.68(0.44,1.04)$ & $2.20(1.17,4.16)$ & $1.05(0.96,1.15)$ \\
\hline $\begin{array}{l}\text { Workin } \\
\text { s } / \text { Non-S }\end{array}$ & $0.71(0.65,0.76)$ & $1.00(0.92,1.09)$ & $1.38(1.25,1.52)$ & $1.15(1.07,1.24)$ & $1.63(1.47,1.81)$ & $1.76(1.62,1.90)$ & $0.60(0.53,0.66)$ & $0.97(0.72,1.30)$ & $0.68(0.64,0.73)$ & $1.09(0.76,1.58)$ & $2.17(1.17,3.99)$ & $1.04(0.95,1.13)$ \\
\hline Toys/Terrier & $32,1.53)$ & $0.92)$ & $\pi=$ & $0.68)$ & 0.47 & 0.48 & $2.19(2.00,2.40)$ & $1.75(1.33,2.30)$ & 1. & $2.98(2.15,4$. & $.24,0.68)$ & $1.04)$ \\
\hline Utility/Terrier & $0.92(0.87,0.99)$ & $0.95(0.89,1.01)$ & $0.79(0.73,0.85)$ & $1.11(1.05,1.18)$ & $1.29(1.20,1.39)$ & $1.29(1.22,1.37)$ & $0.40(0.35,0.46)$ & $1.02(0.77,1.34)$ & $1.43(1.35,1.52)$ & $1.09(0.76,1.57)$ & $0.69(0.49,0.96)$ & $1.08(1.01,1.15)$ \\
\hline Working Dogs/Terrier & $0.87(0.83,0.93)$ & $0.87(0.82,0.93)$ & $0.90(0.84,0.95)$ & $1.00(0.95,1.05)$ & $1.24(1.16,1.33)$ & $1.24(1.18,1.31)$ & $0.79(0.73,0.86)$ & $1.34(1.07,1.67)$ & $1.11(1.06,1.17)$ & $1.76(1.32,2.34)$ & $0.68(0.50,0.90)$ & $1.06(1.00,1.13)$ \\
\hline Utility & $0.65(0.60,0.71)$ & $1.12(1.02,1.22)$ & $1.04(0.94,1.15)$ & $1.77(1.62,1.92)$ & $2.75(2.42,3.13)$ & $2.68(2.44,2.94)$ & $0.18(0.16,0.21)$ & $0.58(0.43,0.80)$ & $1.36(1.26,1.47)$ & $0.37(0.25,0.53)$ & $1.70(0.96,3.00)$ & $1.12(1.03,1.23)$ \\
\hline Work & & $35,1.12)$ & $(1.09,1.30)$ & $46,1.72)$ & 00) & .81) & $0.36(0.33,0.40)$ & $0.76(0.59,1.00)$ & $1.05(0.98,1.13)$ & $44,0.80)$ & , 2.87) & \\
\hline ity & .01) & $6,0.98)$ & $(1.06,1.23)$ & $0(0.85,0.95)$ & $1.04)$ & 1.02) & $1.97(1.73,2.24)$ & $1.31(1.00,1.71)$ & $0.78(0.73,0.82)$ & $1.61(1.14,2.27)$ & $0.98(0.68,1.43)$ & $0.99(0.92,1.06)$ \\
\hline
\end{tabular}

The first number is the odds ratio, and the two numbers in the brackets are the CI. Bold: the odds ratio (CI) was marked as statistically significant $(p<0.05)$ when the CI did not cover 1.00.

a A person was reported to have abused an animal. 


\section{Discussion}

\subsection{Breed Identification}

The agreement of breed recognition between the general public and RSPCA inspectors was very low, which is in line with a previous study demonstrating inconsistent breed identification [22]. In light of the inconsistency, instead of assigning a breed for each dog, a potential alternative is to group them by function or more general characteristics into a recognised breed group [36]. Various kennel clubs have adopted similar concepts in their breed group criteria. For instance, in the ANKC, dogs that are originally bred to work with livestock are classified as working dogs, and those developed to assist hunters in retrieving game are classified as gundogs [7]. In this study, breed information provided by the general public and RSPCA inspectors was used to categorise dogs into ANKC breed groups. Consequently, the agreement increased from $23.2 \%$ to $77.8 \%$, with substantial reliability (Cohen's Kappa $=0.69$ ) between the public and trained inspectors. This result suggests that both the general public and inspectors are able to recognize some important and obvious characteristics of the dogs. Hence breed groups, rather than breeds, may be a better and more practical way of classifying breed for shelter research.

\section{2. $R B$ versus $N-R B$}

This study examined the relationship between breed and canine welfare complaints. Specifically, we examined RB/N-RB and different breed groups with respect to their predisposition to be reported for welfare problems. We found there was a greater proportion of RB in the councils' data compared with RSPCA's, which might reflect a low rate of registration of N-RB, mainly crossbred dogs, in the two Queensland regions or that RB dogs were less likely to be involved in poor welfare or cruelty. These findings are supported by a previous study showing that crossbred dogs are at a higher risk of non-accidental injuries as a result of physical abuses, such as beating, throwing and burning, than pure bred dogs [37]. A further analysis of different complaint codes revealed that RB were predisposed to complaints related to "gaming", where owners allowed these dogs to engage in racing, fighting and blood sports. The number of dog fight cases was relatively small [21], so we should interpret them cautiously, although it is likely that dog fighting occurs more frequently than is reported. Credible and actionable evidence of such events is rarely received. One surprising finding was RB dogs were reported more often than N-RB for not receiving adequate veterinary care. Previous research into pet ownership and attitudes to pet care found that owners of shelter-acquired pets, usually mixed breed [38], took their animals for veterinary care more often and were equally willing to spend over $\$ 1000$ on medical treatment for their pets [39] than pets acquired by other means. Finally, our data suggest that many N-RB dogs are not registered, which may make them more likely to be surrendered to a shelter or abandoned when medical care is required. Previous studies have reported higher rates of surrender of N-RB dogs [38]. N-RB dogs were more likely to be involved in complaints related to husbandry practices and abandonment.

\subsection{Breed Groups}

RB dogs were divided into breed groups and strong correlations between the groups, characteristics of the breeds and reasons for being reported were observed. For instance, toy dogs are small and possibly travel with owners more often, and thus, as found in our study, were more likely to be left alone in a car in hot weather. Previous research reports that smaller breeds of dogs are popular in Australia [40], which might help explain the number of complaints about toy dogs being left unattended in hot vehicles, as reported previously [21]. However, increased awareness of the dangers for dogs in hot cars through regular campaigning on this issue may also explain the high number of reports received [41]. Many terriers, especially those with some pit bull type characteristics (e.g., Staffordshire bull terrier, American Staffordshire terrier, and pit bull terrier), are considered aggressive and dangerous [15], therefore would be predisposed to being reported for abandonment, 
dog fights and cruelty $[17,19,37,42]$. Finally, utility and working dogs are mostly bred for guarding, rescuing or herding functions [7], and are generally energetic and require exercise [43,44]. These breeds were reported for not receiving adequate exercise. In contrast, toy breeds were the least likely to be reported for insufficient exercise, which is in agreement with previous research that found that smaller dogs were likely to have their exercise needs met even though they were walked less frequently [45].

\subsection{Practical Application}

This study provides fundamental information about the relationship between breed groups and various types of welfare complaints in dogs. The information can be used to develop education campaigns to increase awareness of what is involved in adequately and appropriately caring for dogs. Specific breeds have specific needs with respect to, for example, exercise requirements and cognitive enrichment to ensure their welfare is good. Information could be made available to prospective new owners of specific breeds to improve their understanding of the breed and its care requirements. Such information could also inform decision-making around breed choice as requirements of the breed could be matched with the ability of the owner to provide these needs.

\subsection{Limitations and Need for Future Research}

This was the first study providing fundamental information of the relationship between dog breed and welfare complaints made to a welfare organization with the responsibility of administering the Animal Welfare Act. Future research could focus on common breeds and explore the welfare issues in more detail.

There were several limitations of this present study. First, N-RB dogs contributed $32.7 \%$ of our dataset but only $1.7 \%$ of the total population in the councils' data. This major difference might indicate that N-RB dogs were indeed more susceptible to animal welfare concerns, but might also be affected by: (1) the difficulty of breed recognition [22], (2) the potentially different criteria of breed classification in our data and the councils' data and (3) the possibly lower registration rate of N-RB. Second, complaint codes were made based on public reports, which are likely to be inaccurate, at least in some cases. Third, we compared our data with reference data from the Gold Coast and Ipswich City Councils, urban areas in South East Queensland. The RSPCA cases were collected from a broad geographical area including both urban and rural areas, which may cause some regional bias. There were only $0.76 \%(n=814 / 107,597)$ of cases from the Gold Coast and Ipswich regions. If we only compare the cases in these two regions, our results may be skewed by some less-common breeds that are either reported in our data or the councils' registration. Our data cover the Queensland regions along the East Australian seashore, which are nearly identical to the previous research [46]. Therefore, we decided to use similar methods by comparing our entire data with the councils' data. Given these limitations, the data reported here included canine welfare complaints only in Queensland, and national or global generalization should be made with caution.

\section{Conclusions}

Dog identification classified on the basis of breed groups rather than specific breed had a higher agreement between the public and shelter staff, and thus may serve as a better method of describing dogs involved in welfare reports. N-RB dogs, mainly crossbred dogs, were significantly more likely to be reported for alleged animal welfare concerns, especially poor living conditions and abandonment than RB. In addition, the characteristics of specific breeds, such as size, physical traits and exercise demands, were correlated to the reported complaints. Our results can help to improve public education and awareness raising. Finally, future studies are encouraged to explore in more detail the relationships between breed and welfare issues in dogs.

Author Contributions: Conceptualization, C.J.C.P., H.Y.S. and M.B.A.P.; methodology, H.Y.S., C.J.C.P. and M.B.A.P.; software, H.Y.S. and C.J.C.P.; validation, H.Y.S., C.J.C.P. and M.B.A.P.; formal analysis, H.Y.S.; investigation, H.Y.S.; resources, M.B.A.P. and C.J.C.P.; data curation, C.J.C.P., H.Y.S. and M.B.A.P.; writing-original draft preparation, 
H.Y.S.; writing-review and editing, C.J.C.P., M.B.A.P. and H.Y.S.; visualisation, H.Y.S.; supervision, C.J.C.P. and M.B.A.P.; project administration, C.J.C.P. and M.B.A.P.

Funding: This research received no external funding.

Acknowledgments: We thank RSPCA, Qld, for providing the database of canine welfare complaints, RPSCA inspectors for the consultation, and Gold Coast and Ipswich councils for providing the breed registration data.

Conflicts of Interest: Mandy Paterson is employed as the principal scientist by RSPCA, Qld, but none of the authors received any interest or financial support from people or organisations that inappropriately influenced this study.

\section{Appendix A}

Table A1. Description of each complaint code alleging a welfare issue.

\begin{tabular}{|c|c|c|}
\hline Complaint Code & \multicolumn{2}{|c|}{ Description } \\
\hline Abandonment & \multicolumn{2}{|c|}{$\begin{array}{l}\text { An animal was abandoned/left by the owner either at their abode or } \\
\text { somewhere else such as in the bush. }\end{array}$} \\
\hline Baiting/poisoning & \multicolumn{2}{|c|}{ An animal was poisoned or planned to be poisoned. } \\
\hline $\begin{array}{l}\text { Cause captive animal to be } \\
\text { injured/killed by dog }\end{array}$ & \multicolumn{2}{|c|}{ A person let a captive animal be injured/killed by a dog. } \\
\hline Cruelty & \multicolumn{2}{|c|}{ A person was reported to have abused an animal. } \\
\hline $\begin{array}{l}\text { Dog fighting or other prohibited } \\
\text { offence }\end{array}$ & \multicolumn{2}{|c|}{$\begin{array}{l}\text { A person was reported as allowing dogs to fight or conducting other } \\
\text { specifically prohibited acts. }\end{array}$} \\
\hline Emergency relief & \multicolumn{2}{|c|}{$\begin{array}{l}\text { Emergency relief is required for an animal left unattended because its } \\
\text { owner experienced an emergency (e.g., flood or being hit by a car). }\end{array}$} \\
\hline Hot animal in car & \multicolumn{2}{|c|}{ An animal was left unattended in a car during hot weather. } \\
\hline Insufficient food and/or water & \multicolumn{2}{|c|}{ An animal has insufficient food and/or water. } \\
\hline $\begin{array}{l}\text { Keep or use animal for } \\
\text { blooding/coursing a dog }\end{array}$ & \multicolumn{2}{|c|}{ A person used a live bait for blooding/coursing a dog. } \\
\hline $\begin{array}{l}\text { Knowingly allow an animal to } \\
\text { kill/injure another }\end{array}$ & \multicolumn{2}{|c|}{$\begin{array}{l}\text { A person allows one animal to kill/injuring another one, and does } \\
\text { nothing to stop them. }\end{array}$} \\
\hline No exercise/confined/tethered & \multicolumn{2}{|c|}{$\begin{array}{c}\text { An animal is confined or tethered and not given a suitable amount of } \\
\text { exercise. }\end{array}$} \\
\hline No shelter & \multirow{6}{*}{\multicolumn{2}{|c|}{$\begin{array}{c}\text { An animal is not provided with suitable shelter provisions. } \\
\text { An animal did not receive appropriate medical treatment when needed. } \\
\text { The number of animals was too high for the living space provided. } \\
\text { The general condition of an animal is poor. (e.g., messy/matted coat, } \\
\text { pussy eyes, etc.) } \\
\text { The living environment of the animal is poor. } \\
\text { An owner violated a prohibition order. } \\
\text { a } \\
\text { Tail docking or other surgical procedure (e.g., declaw removal, etc.) was } \\
\text { conducted on an animal. }\end{array}$}} \\
\hline $\begin{array}{l}\text { No treatment } \\
\text { Overcrowding }\end{array}$ & & \\
\hline Poor dog condition & & \\
\hline Poor living condition & & \\
\hline Prohibition order breached & & \\
\hline $\begin{array}{l}\text { Tail docking or other surgical } \\
\text { procedure }\end{array}$ & & \\
\hline \multicolumn{3}{|c|}{$\begin{array}{l}\text { a Prohibition order: A prohibition order is given by the court when a person convicted of an animal welfare offense } \\
\text { must not possess any or specific animal for a prescribed period of time [2]. }\end{array}$} \\
\hline \multicolumn{3}{|c|}{ Table A2. Breed list. } \\
\hline Comment from the Public & Breed List & Breed Group \\
\hline Affenpinscher & Affenpinscher & Toys \\
\hline Afghan hound & Afghan hound & Hounds \\
\hline Airedale terrier & Airedale terrier & Terrier \\
\hline Akita & Akita & Utility \\
\hline Alaskan husky & Siberian husky & Utility \\
\hline Alaskan malamute & Alaskan malamute & Utility \\
\hline American bulldog & American bulldog & Non-sporting \\
\hline American foxhound & Foxhound & Hounds \\
\hline American pit bull terrier & Pit bull terrier & Terrier \\
\hline American Staffordshire terrier & Staffordshire terrier & Terrier \\
\hline American water spaniel & American water spaniel & Gundogs \\
\hline Anatolian shepherd dog & Anatolian shepherd dog & Utility \\
\hline
\end{tabular}


Table A2. Cont.

\begin{tabular}{|c|c|c|}
\hline Comment from the Public & Breed List & Breed Group \\
\hline Australian bandog & Cross breed & N-RB \\
\hline Australian bulldog & Australian bulldog & Non-sporting \\
\hline $\begin{array}{l}\text { Australian bulldog cross } \\
\text { Australian cattle dog }\end{array}$ & Australian cattle dog & Working dogs \\
\hline Australian koolie & Coolie/koolie & N-RB \\
\hline Australian sheepdog & Australian sheepdog & Working dogs \\
\hline Australian shepherd & Australian shepherd & Working dogs \\
\hline Australian silky terrier & Australian silky terrier & Toys \\
\hline Australian stumpy tail cattle dog & Australian stumpy tail cattle dog & Working dogs \\
\hline Australian terrier & Australian terrier & Terrier \\
\hline Bandogge mastiff & Cross breed & N-RB \\
\hline Basenji & Basenji & Hounds \\
\hline Basset fauve de Bretagne & Basset fauve de Bretagne & Hounds \\
\hline Basset hound & Basset hound & Hounds \\
\hline Beagle & Beagle & Hounds \\
\hline Bearded collie & Bearded collie & Working dogs \\
\hline Bedlington terrier & Bedlington terrier & Terrier \\
\hline Belgian shepherd & & Working dogs \\
\hline Belgian shepherd-Groenendael & & Working dogs \\
\hline Belgian shepherd-Laekenois & Belgian shepherd & Working dogs \\
\hline Belgian shepherd-Malinois & & Working dogs \\
\hline Belgian shepherd-Tervueren & & Working dogs \\
\hline Bernese mountain dog & Bernese mountain dog & Utility \\
\hline Bichon frise & Bichon frise & Toys \\
\hline Bloodhound & Bloodhound & Hounds \\
\hline Bluetick coohound & Bluetick coohound & Hounds \\
\hline Border collie $\times$ Labrador & Border collie & Working dogs \\
\hline \multicolumn{3}{|l|}{ Border collie, miniature } \\
\hline Border terrier & Border terrier & Terrier \\
\hline Borzoi & Borzoi & Hounds \\
\hline Boston terrier & Boston terrier & Non-sporting \\
\hline $\begin{array}{l}\text { Bouvier des flandres } \\
\text { Boxer }\end{array}$ & Bouvier des Flandres & Working dogs \\
\hline $\begin{array}{c}\text { Boxer cross } \\
\text { Boxer } \times \text { bullmastif }\end{array}$ & Boxer & Utility \\
\hline \multicolumn{3}{|l|}{ Boxer $\times$ American Staffordshire terrier } \\
\hline Bracco Italiano & Bracco Italiano & Gundogs \\
\hline Briard & Briard & Working dogs \\
\hline British bulldog & British bulldog & Non-sporting \\
\hline Brittany & Brittany & Gundogs \\
\hline $\begin{array}{c}\text { Bull Arab } \\
\text { Bull Arab } \times \text { greyhound } \\
\text { Bull terrier }\end{array}$ & Bull Arab & N-RB \\
\hline Bull terrier cross & Bull terrier & Terrier \\
\hline \multicolumn{3}{|l|}{ Bull Terrier, miniature } \\
\hline $\begin{array}{l}\text { Bulldog } \\
\text { Bulldog cross }\end{array}$ & British bulldog & Non-sporting \\
\hline Bullmastiff & Bullmastiff & \\
\hline Bullmastiff cross & & Utility \\
\hline \multicolumn{3}{|l|}{ Bullmastiff $\times$ wolfhound $\times$ Great Dane } \\
\hline Cane corso (Italian mastiff) & Cane corso & Utility \\
\hline Canaan dog & Canaan dog & Non-sporting \\
\hline Cairn terrier & Cairn terrier & Terrier \\
\hline $\begin{array}{c}\text { Cattle dog } \\
\text { Cattle dog cross }\end{array}$ & Australian cattle dog & Working dogs \\
\hline
\end{tabular}


Table A2. Cont.

\begin{tabular}{|c|c|c|}
\hline Comment from the Public & Breed List & Breed Group \\
\hline Cavalier King Charles spaniel & Cavalier King Charles spaniel & Toys \\
\hline Central Asian shepherd dog & Central Asian shepherd dog & Utility \\
\hline Cesky terrier & Cesky terrier & Terrier \\
\hline $\begin{array}{l}\text { Chesapeake Bay retriever } \\
\text { Chihuahua }\end{array}$ & Chesapeake Bay retriever & Gundogs \\
\hline $\begin{array}{c}\text { Chihuahua cross } \\
\text { Chihuahua } \times \text { Jack Russell } \\
\text { Long hair chihuahua }\end{array}$ & Chihuahua & Toys \\
\hline $\begin{array}{l}\text { Chinese crested dog } \\
\text { Chinese crested dog-powder puff }\end{array}$ & Chinese crested dog & Toys \\
\hline Chow chow & Chow chow & Non-sporting \\
\hline Clumber spaniel & Clumber spaniel & Gundogs \\
\hline $\begin{array}{c}\text { Cocker spaniel } \\
\text { Cocker spaniel, American } \\
\text { Cocker spaniel, English }\end{array}$ & Cocker spaniel & Gundogs \\
\hline $\begin{array}{l}\text { Collie } \\
\text { Collie rough } \\
\text { Collie smooth } \\
\text { Corgi }\end{array}$ & Collie & Working dogs \\
\hline $\begin{array}{l}\text { Corgi, Cardigan Welsh } \\
\text { Corgi, Pembroke Welsh } \\
\text { Corgi } \times \text { fox terrier }\end{array}$ & Corgi & Working dogs \\
\hline Coton de Tulear & Coton de Tulear & Toys \\
\hline Cross breed & Cross breed & N-RB \\
\hline Curly coated retriever & Curly coated retriever & Gundogs \\
\hline $\begin{array}{c}\text { Dachshund } \\
\text { Dachshund, long-haired } \\
\text { Dachshund, miniature }\end{array}$ & Dachshund & Hounds \\
\hline $\begin{array}{l}\text { Dalmatian } \\
\text { Dalmatian cross }\end{array}$ & Dalmatian & Non-sporting \\
\hline Dandie dinmont terrier & Dandie dinmont terrier & Terrier \\
\hline Deerhound & Deerhound & Hounds \\
\hline $\begin{array}{c}\text { Dingo } \\
\text { Dingo cross }\end{array}$ & Cross breed & N-RB \\
\hline Dobermann & Dobermann & Utility \\
\hline Dogue de Bordeaux & Dogue de Bordeaux & Utility \\
\hline Dunker & Dunker & Hounds \\
\hline Dutch shepherd & Dutch shepherd & Working dogs \\
\hline English foxhound & Foxhound & Hounds \\
\hline English pointer & English pointer & Gundogs \\
\hline English mastiff & English mastiff & Utility \\
\hline English setter & English setter & Gundogs \\
\hline English springer spaniel & Springer spaniel & Gundogs \\
\hline English toy terrier & English toy terrier & Toys \\
\hline Field spaniel & Field spaniel & Gundogs \\
\hline Finnish lapphund & Finnish lapphund & Working dogs \\
\hline Flat coated retriever & Flat coated retriever & Gundogs \\
\hline Formosan mountain dog (Taiwan dog) & Formosan mountain dog & Utility \\
\hline $\begin{array}{l}\text { Fox terrier } \\
\text { Fox terrier, smooth }\end{array}$ & Fox terrier & Terrier \\
\hline Foxhound & Foxhound & Hounds \\
\hline French bulldog & French bulldog & Non-sporting \\
\hline German coolie & Coolie/koolie & N-RB \\
\hline German hunting terrier & German hunting terrier & Terrier \\
\hline German pinscher & German pinscher & Utility \\
\hline $\begin{array}{l}\text { German shepherd } \\
\text { German shepherd cross }\end{array}$ & German shepherd & Working dogs \\
\hline $\begin{array}{l}\text { German shorthaired pointer } \\
\text { German spitz }\end{array}$ & $\begin{array}{l}\text { German shorthaired/wirehaired pointer } \\
\text { Spitz }\end{array}$ & $\begin{array}{l}\text { Gundogs } \\
\text { Non-sporting }\end{array}$ \\
\hline
\end{tabular}


Table A2. Cont.

\begin{tabular}{|c|c|c|}
\hline Comment from the Public & Breed List & Breed Group \\
\hline German wirehaired pointer & German shorthaired/wirehaired pointer & Gundogs \\
\hline Glen of Imaal terrier & Glen of Imaal terrier & Terrier \\
\hline Golden retriever & Golden retriever & Gundogs \\
\hline Gordon setter & Gordon setter & Gundogs \\
\hline Great Dane & & \\
\hline Great dane $\times$ bull Arab & Great Dane & Non-sporting \\
\hline \multicolumn{3}{|l|}{ Great dane $\times$ bullmastiff } \\
\hline Great Pyrenees & Great Pyrenees & Working dogs \\
\hline Greater Swiss mountain dog & Greater Swiss mountain dog & Working dogs \\
\hline Greyhound & Greyhound & Hounds \\
\hline Griffon Bruxellois & Griffon Bruxellois & Toys \\
\hline Harrier & Harrier & Hounds \\
\hline Havanese & Havanese & Toys \\
\hline Hungarian vizsla & Hungarian vizsla & Gundogs \\
\hline $\begin{array}{l}\text { Husky } \\
\text { Husky cross }\end{array}$ & Siberian husky & Utility \\
\hline $\begin{array}{l}\text { Musky cross } \\
\text { lbizan hound }\end{array}$ & Ibizan hound & Hounds \\
\hline Irish red and white setter & & Gundogs \\
\hline Irish setter & Irish setter & Gundogs \\
\hline Irish terrier & Irish terrier & Terrier \\
\hline Irish water spaniel & Irish water spaniel & Gundogs \\
\hline Irish wolfhound & Irish wolfhound & Hounds \\
\hline Italian greyhound & Italian greyhound & Toys \\
\hline Italian spinone & Italian spinone & Gundogs \\
\hline Jack Russell terrier & Jack Russell terrier & Terrier \\
\hline Japanese chin & Japanese chin & Toys \\
\hline Japanese spitz & Spitz & Non-sporting \\
\hline Kangal shepherd dog & Kangal shepherd dog & Utility \\
\hline Keeshond & Keeshond & Non-sporting \\
\hline \multicolumn{3}{|l|}{ Kelpie cross } \\
\hline Kelpie $\times$ staffordshire terrier & & \\
\hline Kelpie $\times$ border collie & Kelpie & Working dogs \\
\hline \multicolumn{3}{|l|}{ Kelpie $\times$ cattle dog } \\
\hline \multicolumn{3}{|l|}{ Kelpie $\times$ labrador } \\
\hline \multicolumn{3}{|l|}{ Kelpie $\times$ dingo } \\
\hline Kerry blue terrier & Kerry blue terrier & Terrier \\
\hline King Charles spaniel & King Charles spaniel & Toys \\
\hline Kuvasz & Kuvasz & Working dogs \\
\hline Labrador retriever & Labrador retriever & Gundore \\
\hline \multirow{2}{*}{\multicolumn{3}{|c|}{ Labradoodle }} \\
\hline & & \\
\hline Lagotto Romagnolo & Lagotto Romagnolo & Gundogs \\
\hline Lakeland terrier & Lakeland terrier & Terrier \\
\hline Large Munsterlander & Large Munsterlander & Gundogs \\
\hline Leonberger & Leonberger & Utility \\
\hline Large terrier cross & Terrier & Terrier \\
\hline Lancashire heeler & Lancashire heeler & Working dogs \\
\hline Lhasa apso & Lhasa apso & Non-sporting \\
\hline Louisiana Catahoula leopard dog & Louisiana Catahoula leopard dog & Working dogs \\
\hline Löwchen & Löwchen & Toys \\
\hline Lurcher & Cross breed & N-RB \\
\hline Maltese & Maltese & \\
\hline \multicolumn{3}{|l|}{ Maltese cross } \\
\hline Manchester terrier & Manchester terrier & Terrier \\
\hline Maremma sheepdog & Maremma sheepdog & Working dogs \\
\hline Mastiff & & \\
\hline Mastiff cross & Mastiff & Utility \\
\hline Mastiff $\times$ bull Arab & & \\
\hline
\end{tabular}


Table A2. Cont.

\begin{tabular}{|c|c|c|}
\hline Comment from the Public & Breed List & Breed Group \\
\hline $\begin{array}{c}\text { Medium terrier } \\
\text { Medium terrier cross }\end{array}$ & Terrier & Terrier \\
\hline Miniature fox terrier & Fox Terrier & Terrier \\
\hline Miniature pinscher & Miniature pinscher & Toys \\
\hline Neapolitan mastiff & Neapolitan mastiff & Utility \\
\hline New Zealand huntaway & New Zealand huntaway & Working dogs \\
\hline Newfoundland & Newfoundland & Utility \\
\hline Norfolk terrier & Norfolk terrier & Terrier \\
\hline North Queensland bullhound & Cross breed & N-RB \\
\hline Norwegian elkhound & Norwegian elkhound & Hounds \\
\hline Norwich terrier & Norwich terrier & Terrier \\
\hline Nova Scotia duck tolling retriever & Nova Scotia duck tolling retriever & Gundogs \\
\hline Old English sheepdog & Old English sheepdog & Working dogs \\
\hline Papillon & Papillon & Toys \\
\hline Parson Russell terrier & Parson Russell terrier & Terrier \\
\hline Pekingese & Pekingese & Toys \\
\hline Peruvian hairless dog & Peruvian hairless dog & Hounds \\
\hline Petit basset griffon vendeen & Petit basset griffon vendeen & Hounds \\
\hline Pharaoh hound & Pharaoh hound & Hounds \\
\hline Pit bull terrier & Pit bull terrier & Terrier \\
\hline Pig dog & Cross breed & Terrier \\
\hline Pointer & Pointer & Gundogs \\
\hline Polish lowland sheepdog & Polish lowland sheepdog & Working dogs \\
\hline $\begin{array}{l}\text { Pomeranian } \\
\text { Poodle }\end{array}$ & Pomeranian & Toys \\
\hline $\begin{array}{c}\text { Poodle toy } \\
\text { Poodle miniature } \\
\text { Poodle standard } \\
\text { Poodle } \times \text { shih tzu }\end{array}$ & Poodle & Non-sporting \\
\hline Portugese podengo & Portugese podengo & Hounds \\
\hline Portuguese water dog & Portuguese water dog & Utility \\
\hline Pug & Pug & Toys \\
\hline Puli & Puli & Working dogs \\
\hline Prague ratter & Cross breed & N-RB \\
\hline Pyrenean mastiff & Pyrenean mastiff & Utility \\
\hline Pyrenean mountain dog & Pyrenean mountain dog & Utility \\
\hline Rhodesian ridgeback & Rhodesian ridgeback & Hounds \\
\hline $\begin{array}{c}\text { Rottweiler } \\
\text { Rottweiler } \times \text { mastiff }\end{array}$ & Rottweiler & Utility \\
\hline Russian black terrier & Russian black terrier & Utility \\
\hline Saint bernard & Saint bernard & Utility \\
\hline Saluki & Saluki & Hounds \\
\hline Samoyed & Samoyed & Utility \\
\hline Sarplaninac & Sarplaninac & Utility \\
\hline Schipperke & Schipperke & Non-sporting \\
\hline \multicolumn{3}{|l|}{ Schnauzer } \\
\hline $\begin{array}{l}\text { Schnauzer, miniature } \\
\text { Schnauzer, standard }\end{array}$ & Schnauzer & Utility \\
\hline \multicolumn{3}{|l|}{ Schnauzer, giant } \\
\hline Scottish terrier & Scottish terrier & Terrier \\
\hline Sealyham terrier & Sealyham terrier & Terrier \\
\hline $\begin{array}{l}\text { Shar pei } \\
\text { Shar Pei cross }\end{array}$ & Shar pei & Non-sporting \\
\hline Shetland sheepdog & Shetland sheepdog & Working dogs \\
\hline Shiba inu & Shiba inu & Utility \\
\hline $\begin{array}{c}\text { Shih tzu } \\
\text { Shih }\end{array}$ & Shih tzu & Non-sporting \\
\hline Siberian husky & Siberian husky & Utility \\
\hline Skye terrier & Skye terrier & Terrier \\
\hline
\end{tabular}


Table A2. Cont.

\begin{tabular}{|c|c|c|}
\hline Comment from the Public & Breed List & Breed Group \\
\hline Sloughi & Sloughi & Hounds \\
\hline Small terrier cross & Terrier & Terrier \\
\hline Smithfield cattle dog & Cross breed & $\mathrm{N}-\mathrm{RB}$ \\
\hline Soft coated wheaten terrier & Soft coated wheaten terrier & Terrier \\
\hline Spaniel & Spaniel & Gundogs \\
\hline Spanish water dog & Spanish water dog & Gundogs \\
\hline Spitz & Spitz & Non-sporting \\
\hline Spoodle & Cocker spaniel & Gundogs \\
\hline $\begin{array}{l}\text { Staffordshire bull terrier } \\
\text { Staffordshire bull terrier } \times \text { labrador }\end{array}$ & American Staffordshire bull terrier & Terrier \\
\hline Staghound & Staghound & N-RB \\
\hline Swedish vallhund & Swedish vallhund & Working dogs \\
\hline Tenterfield terrier & Tenterfield terrier & Terrier \\
\hline Terrier & Terrier & Terrier \\
\hline Thai ridgeback & Thai ridgeback & Hounds \\
\hline Tibetan mastiff & Tibetan mastiff & Utility \\
\hline Tibetan spaniel & Tibetan spaniel & Toys \\
\hline Tibetan terrier & Tibetan terrier & Non-sporting \\
\hline Timber shepherd & Cross breed & N-RB \\
\hline Weimaraner & Weimaraner & Gundogs \\
\hline Welsh springer spaniel & Springer spaniel & Gundogs \\
\hline Welsh terrier & Welsh terrier & Terrier \\
\hline West highland white terrier & West highland white terrier & Terrier \\
\hline Whippet & Whippet & Hounds \\
\hline White Swiss shepherd dog & White Swiss shepherd dog & Working dogs \\
\hline Wirehaired fox terrier & Fox terrier & Terrier \\
\hline Xoloitzcuintle & Xoloitzcuintle & Non-sporting \\
\hline Yorkshire terrier & Yorkshire terrier & Toys \\
\hline
\end{tabular}

ANKC: Australian National Kennel Council (http://ankc.org.au/); AMKC: American Kennel Club (https://www.akc. org/dog-breeds/); UKC: United Kennel Club (https://www.ukcdogs.com/breed-standards); NZKC: New Zealand Kennel Club (https://www.dogsnz.org.nz/home/home).

\section{References}

1. Tallichet, S.E.; Hensley, C. Rural and urban differences in the commission of animal cruelty. Int. J. Offender Ther. 2005, 49, 711-726. [CrossRef] [PubMed]

2. Queensland Government-Department of Agriculture and Fisheries. Animal Care and Protection Act 2001. Available online: https://www.legislation.qld.gov.au/view/pdf/inforce/current/act-2001-064 (accessed on 22 April 2019).

3. Mogbo, T.C.; Oduah, F.N.; Okeke, J.J.; Ufele, A.N.; Nwankwo, O.D. Animal cruelty: A review. J. Nat. Sci. Res. 2013, 3, 94-98.s.

4. Newberry, M. Associations between different motivations for animal cruelty, methods of animal cruelty and facets of impulsivity. Psychol. Crime Law 2018, 24, 500-526. [CrossRef]

5. Hare, B. Domestication experiments reveal developmental link between friendliness and cognition. J. Bioecon. 2018, 20, 159-163. [CrossRef]

6. Savolainen, P.; Zhang, Y.-P.; Luo, J.; Lundeberg, J.; Leitner, T. Genetic evidence for an east asian origin of domestic dogs. Science 2002, 298, 1610-1613. [CrossRef] [PubMed]

7. Australian National Kennel Council LTD. Breeds. Available online: http://ankc.org.au/Home (accessed on 19 November 2018).

8. American Kennel Club. Greyhound. Available online: https://www.akc.org/dog-breeds/greyhound/ (accessed on 19 November 2018).

9. Arvelius, P.; Malm, S.; Svartberg, K.; Strandberg, E. Measuring herding behavior in Border collie-effect of protocol structure on usefulness for selection. J. Vet. Behav. 2013, 8, 9-18. [CrossRef]

10. United Kennel Club. Border Collie. Available online: https://www.ukcdogs.com/border-collie (accessed on 13 March 2019). 
11. McEwan, A.; Skandakumar, K. The welfare of greyhounds in Australian racing: Has the industry run its course? Aust. Anim. Prot. Law J. 2011, 6, 52-74.

12. Stafford, K. The welfare of the athletes; greyhounds and sled dogs. In The welfare of dogs; Phillips, C., Ed.; Springer: Dordrecht, The Netherlands, 2006; pp. 143-160, ISBN 978-140-204-361-1.

13. Atkinson, M.; Young, K. Reservior dogs: Greyhound racing, mimesis and sports-related violence. Int. Rev. Sociol. Sport 2005, 40, 335-356. [CrossRef]

14. Zilocchi, M.; Tagliavini, Z.; Cianni, E.; Gazzano, A. Effects of physical activity on dog behavior. Dog Behav. 2016, 2, 9-14. [CrossRef]

15. Collier, S. Breed-specific legislation and the pit bull terrier: Are the laws justified? J. Vet. Behav. 2006, 1, 17-22. [CrossRef]

16. Australian Government-Federal Register of Legislation. Animals (Importation of Certain Dog Breeds) Regulations 2004 (NI). Available online: https://www.legislation.gov.au/Details/C2018Q00020 (accessed on 31 May 2019).

17. Tarver, E.C. The dangerous individual('s) dog: Race, criminality and the 'Pit bull'. Cul. Theor. Criti. 2014, 55, 273-285. [CrossRef]

18. Devin, B. Breed specific legislation: Unfair prejudice \& (and) ineffective policy. Animal l. 2004, 10, 313.

19. Kalof, L.; Taylor, C. The discourse of dog fighting. Humanit. Soc. 2007, 31, 319-333. [CrossRef]

20. Johnson, O. Dog fighting and the growing social epidemic of animal cruelty. J. Law Enf. 2014, 3, 1-9.

21. Shih, H.Y.; Paterson, M.B.A.; Phillips, C.J.C. A Retrospective Analysis of Complaints to RSPCA Queensland, Australia, about Dog Welfare. Animals 2019, 9, 282. [CrossRef] [PubMed]

22. Voith, V.L.; Trevejo, R.; Dowling-Guyer, S.; Chadik, C.; Marder, A.; Johnson, V.; Irizarry, K. Comparison of visual and DNA breed identification of dogs and inter-observer reliability. Am. J. Sociol. Res. 2013, 3, 17-29. [CrossRef]

23. Mehrkam, L.R.; Clive, D.L.W. Behavioral differences among breeds of domestic dogs (Canislupus familiaris): Current status of the science. Appl. Anim. Behav. Sci. 2014, 155, 12-27. [CrossRef]

24. Gunter, L.M.; Barber, R.T.; Wynne, C.D.L. What's in a name? Effect of breed perceptions \& labeling on attractiveness, adoptions \& length of stay for pit-bull-type dogs. PLoS ONE 2015, 11, e0146857. [CrossRef]

25. Clarke, T.; Mills, D.; Cooper, J. "Type" as central to perceptions of breed differences in behavior of domestic dog. Soc. Anim. 2016, 24, 467-485. [CrossRef]

26. Olson, K.R.; Levy, J.K.; Norby, B.; Crandall, M.M.; Broadhurst, J.E.; Jacks, S.; Barton, R.C.; Zimmerman, M.S. Inconsistent identification of pit bull-type dogs by shelter staff. Vet. J. 2015, 206, 197-202. [CrossRef]

27. Shih, H.Y.; Paterson, M.B.A.; Phillips, C.J.C. Socioeconomic influences on reports of canine welfare concerns to the RSPCA in Queensland, Australia. Animals 2019 (under review).

28. New Zealand Kennel Club. Recognised Pedigree Breeds. Available online: https://www.dogsnz.org.nz/ home/home (accessed on 1 August 2018).

29. American Kennel Club. Dog Breeds. Available online: https://www.akc.org/dog-breeds/ (accessed on 1 Augst 2018).

30. United Kennel Club. Breed Standards. Available online: https://www.ukcdogs.com/breed-standards (accessed on 1 August 2018).

31. Landis, J.R.; Koch, G.G. The measurement of observer agreement for categorical data. Int. Biom. Soc. 1997, 33, 159-174. [CrossRef]

32. City of Gold Coast. Dog Registration. Available online: https://cogc.cloud.infor.com/ePathway/epthprod/ Web/Animals/AnimalClasses.aspx?js=1900370700 (accessed on 17 June 2019).

33. City of Ipswich. New Dog Registration. Available online: https://epathway.ipswich.qld.gov.au/ePathway/ Production/Web/Animals/AnimalClasses.aspx?js=1151207821 (accessed on 17 June 2019).

34. Minitab ${ }^{\circledR}$, Salford Predictive Modeler ${ }^{\circledR}$. Introduction to Logistic Regression Modeling. Available online: https://minitab.com/uploadedFiles/Content/Products/SPM/IntroLOGIT.pdf (accessed on 17 June 2019).

35. Minitab ${ }^{\circledR}$ 18. Perform Stepwise Regression for Fit Regression Model. Available online: https://support.minitab.com/en-us/minitab/18/help-and-how-to/modeling-statistics/regression/howto/fit-regression-model/perform-the-analysis/perform-stepwise-regression/ (accessed on 17 June 2019).

36. Simpson, R.J.; Simpson, K.J.; VanKavage, L. Rethinking dog breed identification in veterinary practice. J. Am. Vet. Med. Assoc. 2012, 241, 1163-1166. [CrossRef] [PubMed] 
37. Murno, H.M.C.; Thrusfield, M.V. Battered pets': Non-accidental physical injuries found in dogs and cats. J. Small Anim. Pract. 2001, 42, 279-290. [CrossRef]

38. New, J.C.J.; Salman, M.D.; King, M.; Scarlett, J.M.; Kass, P.H.; Hutchison, J.M. Characteristics of shelter-relinquished animals and their owners compared with animals and their owners in U.S. pet-owning households. J. Appl. Anim. Welf. Sci. 2000, 3, 179-201. [CrossRef]

39. Freiwald, A.; Litster, A.; Weng, H.Y. Survey to investigate pet ownership and attitudes to pet care in metropolitan Chicago dog and/or cat owners. Prev. Vet. Med. 2014, 115, 198-204. [CrossRef] [PubMed]

40. Teng, K.T.; McGreevy, P.D.; Toribio, J.-A.L.M.L.; Dhand, N.K. Trends in popularity of some morphological traits of purebred dogs in Australia. Canine Genet. Epidemiol. 2016, 3, 1-9. [CrossRef] [PubMed]

41. RSPCA Queensland. Keep Pets out of Hot Cars. Available online: https://www.rspcaqld.org.au/blog/petcare/dogs-in-hot-cars (accessed on 19 June 2019).

42. Burley, S. My dog's the champ: An analysis of young people in urban settings and fighting dog breeds. Anthropol. Matters J. 2008, 10, 1-18.

43. Lim, C.; Rhodes, R.E. Sizing up physical activity: The relationships between dog characteristics, dog owners' motivations, and dog walking. Psychol. Sport Exerc. 2016, 24, 65-71. [CrossRef]

44. Westgarth, C.; Christian, H.E.; Christley, R.M. Factors associated with daily walking of dogs. BMC Vet. Res. 2015, 11, 116-128. [CrossRef]

45. Pickup, E.; German, A.J.; Blackwell, E.; Evans, M.; Westgarth, C. Variation in activity levels amongst dogs of different breeds: results of a large online survey of dog owners from the UK. J. Nutr. Sci. 2017, 6, 1-7. [CrossRef] [PubMed]

46. Schot, A.A.W.-v.d.; Day, C.; Morton, J.M.; Rand, J.; Phillips, C.J.C. Risk factors for behavior problems in cats presented to an Australian companion animal behavior clinic. J. Vet. Behav. 2016, 14, 34-40. [CrossRef]

(C) 2019 by the authors. Licensee MDPI, Basel, Switzerland. This article is an open access article distributed under the terms and conditions of the Creative Commons Attribution (CC BY) license (http://creativecommons.org/licenses/by/4.0/). 